\title{
G \\ TRANSFORMATION CAPITAL: \\ THE CHALLENGE OF DESIGNING \\ AND TESTING A NEW INVESTMENT \\ LOGIC FOR THE SUSTAINABLE \\ DEVELOPMENT GOALS
}

\section{CAPITAL TRANSFORMADOR: \\ EL RETO DE DISEÑAR Y \\ EXPERIMENTAR CON NUEVAS \\ LÓGICAS DE INVERSIÓN PARA \\ LOS OBJETIVOS DE DESARROLLO}

\section{SOSTENIBLE}

\author{
Dominic Hofstetter \\ EIT Climate-KIC \\ dominic.hofstetter@climate-kic.org
}

Fecha recepción artículo: 27/12/2019 • Fecha aprobación del artículo: 12/03/2020

\section{ABSTRACT}

The most tangible and pressing problems of the $21^{\text {st }}$ century are complex systemic issues. Addressing them requires deep structural changes within the socio-technical systems that constitute modern civilization. As financial capital is an important lever of change in such systems, the way in which we deploy capital affects our ability to accomplish the UN's Sustainable Development Goals. The problem is that today's capital markets operate under a set of axioms, paradigms, and structures that make them ill-suited to fuel systemic transformations. There is thus a need for an investment logic that deploys capital with a different intent and mindset and with different methodologies, structures, capabilities, and decision-making frameworks. Residing at the intersection of systems thinking and finance practice, Transformation Capital is such a logic. This article introduces Transformation Capital and discusses how it can be tested through real-world prototyping.

Keywords: Systems, Complexity, Finance, Investment, Innovation 


\section{RESUMEN}

Abordar los sistemas complejos es una de las tareas más apremiantes del siglo XXI. Hacer frente a esta complejidad requiere profundos cambios estructurales en los sistemas sociales que constituyen la civilización moderna. El capital financiero es una de las palancas de cambio más importante en dichos sistemas y, por tanto, la manera en la que lo utilizamos determina nuestra habilidad para alcanzar los Objetivos de Desarrollo Sostenible de Naciones Unidas. Una de las principales barreras hoy en día es que los mercados operan bajo una serie de axiomas, paradigmas y estructuras que dificultan el desarrollo de transformaciones sistémicas. Existe una necesidad, por tanto, de fomentar una nueva mentalidad de inversión que utilice el capital con nuevos propósitos, estructuras, habilidades y diferentes marcos de toma de decisiones. El Capital Transformador representa esa mentalidad, al ubicarse en la intersección de los enfoques sistémicos y las prácticas financieras. Este artículo presenta y desarrolla el concepto de Capital Transformador y reflexiona sobre cómo se puede experimentar a través de la implementación de prototipos en contextos reales.

Palabras clave: Sistemas, Complejidad, Finanzas, Inversión, Innovación

Dominic Hofstetter acts as the Director of Capital and Investments at EIT Climate-KIC, Europe's largest climate innovation initiative. He is responsible for building the organization's nascent investment function around Transformation Capital, a new investment logic at the intersection of systems thinking and finance practice. Before joining EIT Climate-KIC in 2015, Dominic had worked as a renewable energy entrepreneur at Electrochaea, as a private equity investor at Hudson Clean Energy Partners, and as a finance professional at Credit Suisse. He holds an MBA from the University of Chicago and an MSc in Environmental Change and Management from the University of Oxford.

\section{A WORLD IN PERIL}

As we enter the third decade of the 21st century, humankind faces unprecedented challenges: unabated poverty, rising social inequality, deteriorating public health, forced mass migration, accelerating loss of biodiversity, and increasing environmental pollution (World Economic Forum, 2019). Towering above them all is climate change, a threat so existential that it has the potential to eradicate our species.

To safeguard human civilization as we know it, the Intergovernmental Panel on Climate Change (IPCC) is calling for the "rapid, far-reaching an unprecedented" transformation of the socio-technical systems that constitute modern civilization: energy, land-use, infrastructure, industry, maritime systems, and cities (IPCC, 2018, pp. 32). This implies that we must change not only the technologies used to extract, convert, and allocate resources within our economy. We also need to shift values and norms-on both the individual and collective level-and create a balance of political, cultural, and institutional power in society (IPCC, 2018).

Implied in the IPCC's call to action is the notion that the most pressing and tangible problems of our time are not technical in nature-they are systemic. So incremental improvements in single-point solutions-such as new technologies - are not going to unlock change at the pace and scale required. Instead, we need to learn how to weave technological advances into the fabric of society along with other cultural, institutional, social, and economic innovations.

Financial capital is an important lever of change in socio-technical systems. The way in which money accumulates and flows within them has a significant impact on our ability to build a low-carbon economy 
and a climate-resilient, just, and inclusive society. Accordingly, the role of capital is well-recognized for the accomplishment of the UN's Sustainable Development Goals (UNCTAD, 2014). The Paris Agreement even sees "financial flows" as one of three keys-along with greenhouse gas emissions and adaptation measuresto strengthening the global response to the threat of climate change (United Nations, 2015).

The current discourse on climate finance frames the issue largely as a quantity problem. "If only we manage to mobilize sufficient levels of funding, those complex systemic challenges will easily be solved", or so the thinking goes. This is why so many international climate conferences are dominated by a debate about how to close the SDG investment gap. While this investment gap is large-estimated to reach into the trillions of Euros per year (Fetherston, J., 2018) -important questions await capital that has been mobilized. What should that money be invested in if the primary intent is to catalyse systems transformation? How should these investments be made given that the issue is a complex one? And who needs to be part of the investment activity?

The plethora of "sustainable finance" initiatives currently underway have not yet produced compelling answers to these questions. As we enter a decisive decade, it remains largely unclear how capital can be deployed to support the kind of real-economy systems transformation that the IPCC is calling for.

The root of the problem is that today's financial industry is severely limited by its own axioms, paradigms, and structures to fuel transformative change. Given how little time we have left to reverse our emissions trajectory and protect the world's most vulnerable communities, there is now an urgent need to rethink the way society deploys capital over the next decade. We need an investment logic that accelerates the transformation of socio-technical systems; one that deploys capital with a different intent and mindset and with different methodologies, structures, capabilities, and decision-making frameworks.

This is the ambition of Transformation Capital, an investment logic at the intersection of systems thinking and finance practice. In this article, I will first review why present-day capital markets are ill-suited to address complex systemic challenges. I will then describe the contours of a system-transformative investment logic as they have emerged so far. These contours must be understood as a hypothesis, a point of departure for a systematic attempt to develop, test, and mainstream Transformation Capital through an open-innovation initiative.

An investment logic of that scope and ambition cannot be designed at the white board. It must be brought into the field, tested under real-world conditions, and refined based on the learning that emerges. Hence the third part of the article will describe the functions of Transformation Capital prototypes and how such testing environments must be designed to fulfil their purpose.

\section{WHY TODAY'S CAPITAL MARKETS FAIL TO BE TRANSFORMATIVE}

Present-day capital markets operate under a set of axioms that severely inhibit their transformative capacity. Axioms are propositions seen as widely accepted and self-evident, much like first principles in science.

One such axiom is that everything of value must be measurable in monetary terms. Capital markets cannot relate to-or engage with-sources of value outside the narrow definition of money. This affects how risk and return are conceptualised in financial mathematics. Risk is defined as the quantifiable chance of an outcome, the known unknowns. Financial markets thus have no ability to consider and mitigate fundamental uncertainty-non-quantifiable chance, or the unknown unknowns-including tipping points and non- 
linearities. Nor can they account for systemic risks such as the vulnerability of institutions and other social constructs to the radical impacts of wicked problems like climate change.

Similar problems arise through the conceptualisation of return, generally defined as the change in the value of an investment over time. Based on this definition, monetary stock (investment) and flow (change) relate to each other, so investors cannot recognise-let alone appropriate-any value their investments generate outside of this self-referential frame of reference, including positive externalities.

A second axiom is that the future can be predicted, when in fact the world behaves as a complex adaptive system and is thus inherently unpredictable (Buckley, 1968). The implication is that investors rely on probabilistic models to forecast the evolution of the economy at large and of individual assets. Once committed to an investment thesis, investors often lock themselves into a self-created path dependency with little capacity to respond to whatever emerges in the system in which they hold exposure.

To uphold its axioms and ensure conformity with its mathematics, the financial industry embraces and enforces a set of idiosyncratic structures and practices. Finance professionals are educated and socialised through homogeneous courses offered by universities (e.g. business schools) and professional education providers (e.g. the CFA Institute). Knowledge is organised-and decisions are taken-within paradigms that take the form of investment theses, selection approaches (active vs. passive), financial instruments (stocks, bonds, derivatives), asset classes (equity, debt, real estate), and investment horizons (short-term, longterm). Many of the industry's recruitment practices are geared toward maximising cultural and educational fit, which drives conformism and tribalism. Its incentive systems are biased toward short-term profits, which double as determinants of self-worth and social status.

Together, these axiomatic, mathematical, and structural idiosyncrasies make financial markets rigid and strip them of the capacity to adapt and be responsive. In fact, they create a dependency on the status quosystemic stability is beneficial, systemic volatility is detrimental. This status quo dependency is so large that it is self-perpetuating. Investors prefer assets that conform to their axioms, mathematics, and structures because anything else is not investable.

And herein lies the problem: If capital markets depend on-and indeed nurture-the perpetuation of the status quo, they are unlikely to fuel the type of profound transformations the world needs in order to cope with the gravest challenges of the 21st century.

\section{TRANSFORMATION CAPITAL: DIFFERENT INTENT, NEW SPIRIT}

What distinguishes Transformation Capital as an investment logic from traditional finance approaches is its strategic intent. The primary goal is not to maximise the self-replication of capital but to kick or shift human (socio-technical) systems in specific directions. While this does not preclude financial returns, it means that purpose takes precedent over profit.

Implied in this intent is the necessity to articulate a transformation agenda. What does a national government want its economy to look like in the future? How shall a regional transportation system operate? What is a corporation's vision for a more sustainable, inclusive, and resilient supply chain? Problem owners must take a position on the systemic outcomes they are working toward and make a resource commitment to enable such transitions. 
Investing for transformative effects means that investors need to re-imagine the spirit in which capital is deployed. They must choose collaboration over competition and form consortia with a common transformative agenda. They must rethink how risks and rewards are shared across a wider set of interventions-where some are "investable" (in the popular meaning) and others are not-and across public, private, and philanthropic actors. They must select specific investments based not on their individual merits but on the aggregate value they can generate at the systems level. This will sometimes require innovative public-private investment partnerships (Mazzucato and Penna, 2015) and, in the long-term, more progressive financial mathematics.

Investors must also acknowledge that societies, politics, and economies are complex adaptive systems with self-organising dynamics, feedback loops, and non-deterministic and non-linear behaviour. So they must de-emphasise categorisation and specialisation and instead embrace porosity, blurriness, and paradox. And they must embrace structures that promote diversity, multi-disciplinarity, and norms and incentive systems geared for long-term sustainability.

Bringing Transformation Capital to life does not mean overthrowing capitalism or revolutionising the monetary system. While it is evident that today's capitalism is unsustainable, much can be achieved by engaging capital on the basis of its current needs and interests by simply deploying it in a smarter way and on a bigger playing field.

\section{FROM INVESTMENT LOGIC TO INVESTMENT PROGRAMME}

A bigger playing field emerges when capital is deployed in the context of a broader systems intervention strategy that also engages non-investable levers of change: policy and regulatory frameworks, social norms and behaviours, skills and capabilities, citizen participation models, and identities and narratives of communities. Being nested within a broader systems innovation portfolio de-risks the investment proposition while allowing investors to engage the self-transforming properties of adaptive systems in service of their transformative agenda.

Investing with transformative intent requires new capabilities that draw from a broad range of disciplines, including:

- Defining the boundaries of a (socio-technical) system and mapping the nodes and relationships within that system;

- Conjecturing transition pathways and transformation strategies;

- Identifying and engaging Sensitive Intervention Points (SIPs) - those places in a system where a relatively small investment can trigger a larger change that becomes irreversible, and where non-linear feedback effects act as amplifiers (Farmer et al., 2019);

- Convening and orchestrating investor consortia with a common transformative intent, often in innovative forms of private-public investment partnerships that thrive on a fair distribution of risk and return;

- Designing a portfolio of financial instruments-from private and public actors-for directional synergy and complementarity (strategic blending), whilst leveraging public funding through the crowding-in of private capital; 
- Advising public sector officials on how to align financial policies and regulations, fiscal policy levers, and information instruments to create supporting conditions for sustainable financial flows in the long-term (Whitley et al., 2018);

- Right-sizing an investment portfolio commensurate with the challenge and allocating money to individual investment propositions using systems-level sense-making and decision-making frameworks (Axilo, 2019);

- Measuring the effects of the investments on the transition dynamics within the system (Schot, et al., 2019), spread over time and in response to what emerges in the system, and quantifying the transformational return on investment (tROI).

As these points illustrate, Transformation Capital is more than just an investment strategy. This is why I call it a logic-a collection of axioms, paradigms, and structures designed for strategic coherence. This logic illuminates not only why and how systemic investments should be made but also guides decision-making on what should be invested in and who should participate in the investment activity.

As a consequence of its scope and ambition, Transformation Capital cannot be designed through desk research and consultative stakeholder engagement alone. Instead, it must be approached as an inquiry, an iterative learning journey that starts with loosely held definitions and refines those with knowledge gained from real-world experience. We call the contexts in which such learning takes place "Prototypes".

Yet how do you prototype a new investment logic? What purposes must these prototypes serve? And how do prototypes need to be designed in order to achieve their objectives?

\section{PROTOTYPES: LEARNING HOW TO IMPLEMENT A NEW INVESTMENT LOGIC}

A Prototype needs to fulfil three basic functions. The existential function is about providing a space for the new investment logic to come to life. As an impact-motivated and action-oriented initiative, Transformation Capital acquires meaning only through real-world application. A Prototype offers a space for people to convene and collaborate, contextualizes this work, and makes it meaningful for its participants.

The developmental function is about providing a space for learning. Such learning takes place on multiple levels and is iterative, i.e. the experience gained by applying the theories of Transformation Capital produce valuable insights for their subsequent refinement. An emergent outcome of such learning is that people gradually become proficient at systemic investing.

The catalytic function is about creating spillover effects to the Transformation Capital Initiative-an open innovation program looking to develop, test, and mainstream Transformation Capital as an investment logic. A Prototype must offer fertile ground for storytelling, field building, and fundraising. 


\section{EXISTENTIAL FUNCTION: PROTOTYPES AS LIFE SYSTEMS}

A Prototype fulfils its basic existential function through providing a space for people to convene and collaborate on a meaningful problem over an adequate amount of time. Most Prototype settings will find it easy to meet these check-the-box requirements. Yet it is important to also pay attention to qualitative aspects. Like an ecosystem in nature, a Prototype will thrive if it...

- accommodates variety-across multiple dimensions such as actors, relationships, problems, assets, transactions, and disciplines;

- exhibits diversity-across gender, age, and academic, professional, and cultural backgrounds;

- allows for serendipity-of encounters, collaborations, and outcomes; and

- fosters a culture of curiosity, experimentation, and risk-taking.

\section{DEVELOPMENTAL FUNCTION: PROTOTYPES AS LEARNING ENVIRONMENTS}

Learning takes place through the reflections on the outcomes of an experiment. We thus need to ask: What do we want to experiment with? How do we make sense of outcomes? And what is the purpose of our reflections?

\section{OBJECTS OF EXPERIMENTATION}

The Transformation Capital investment logic consists of a set of modules that together form a coherent finance practice (Figure 1). For instance, one module relates to the development of business models to create and capture new sources of value and distribute such value in novel ways. Another module is concerned with the articulation of a transformational investment risk framework.

Figure 1: Transformation Capital Design Space (as of December 2019)

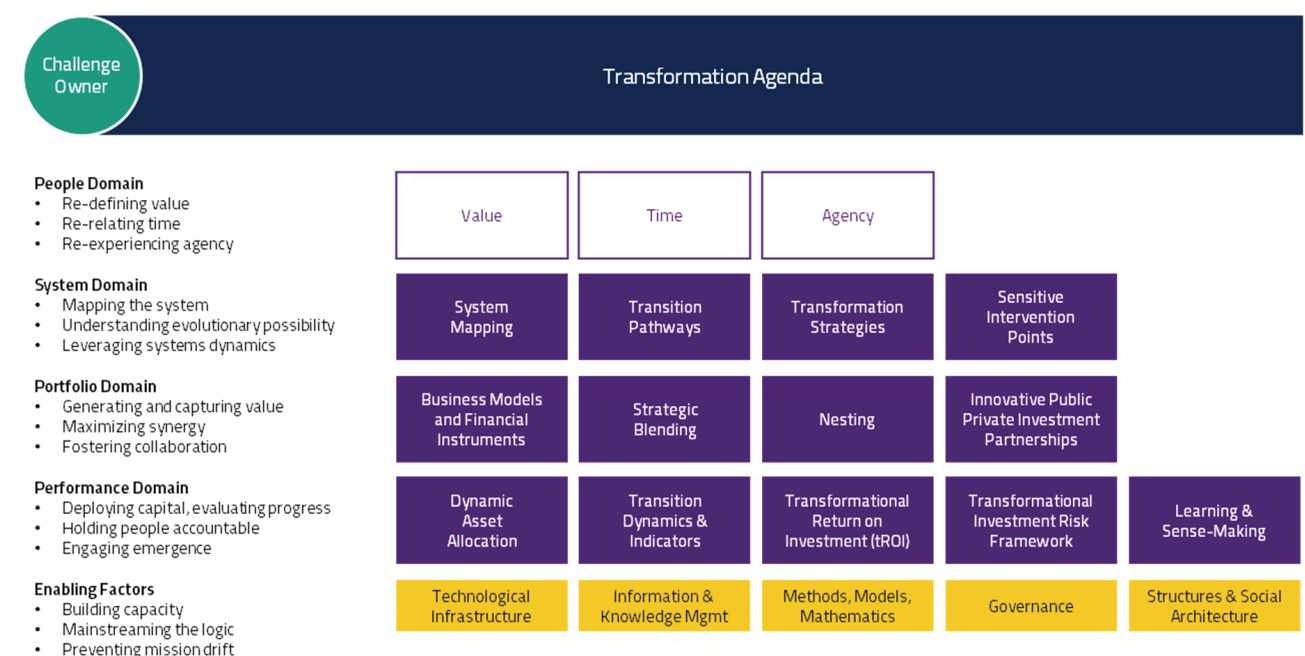


The design space in which these modules sit represents a menu from which a Prototype can choose those that lend themselves well for real-world testing in its specific context. Whilst some Prototypes will strive to do work across the entire design space, others will opt to focus on a limited number of modules.

Once the modules are selected, there is a need to define the learning objectives for each. These provide the basis for capturing and evaluating outcomes.

\section{CAPTURING AND MAKING SENSE OF OUTCOMES}

The process of capturing and evaluating outcomes needs to be structured around an information and knowledge management system. It should follow a rhythm appropriate for the context in which the Prototype takes place and build upon an effective sense-making protocol. Academic supervision will strengthen the rigor of the process, while digital technologies can help with data capture and analysis.

\section{REFLECTING ON OUTCOMES}

The discussion then needs to move to a higher level of abstraction and focus on how well Transformation Capital is accomplishing its primary intent-to catalyse the directional transformative change of sociotechnical systems. The purpose of this learning is to validate (and refine) the theory of change that the type of systemic investment logic described by Transformation Capital can indeed serve its intent.

We are interested in questions of effectiveness on three levels-first, on the level of individual modules (e.g. does a new financial instrument succeed at generating and capturing the intended value?); second, on the level of the collection of modules (e.g. do the instrument, investment partnership, and governance mechanism work well in combination?); and third, on the level of the system (e.g. does the Prototype generate the desired systemic effects?).

\section{META-LEVEL LEARNING: CAPABILITIES}

There is also a higher domain of reflection. On this meta level, we want to learn whether we are learning well. Do we generate the insights we need? Are these insights captured well? Are they being incorporated into the refinement of our investment logic? Are we learning at the right pace? Are all relevant people part of the learning experience? What are we not learning? Given the importance of learning in developing a new investment logic, it is critical to capture reflections on the learning process itself. Over time, such learning will result in the emergence of capabilities, i.e. the skills to do systemic vesting well.

\section{CATALYTIC FUNCTION: PROTOTYPES AS ENABLER OF SCALE}

Like any other innovation initiative, the Transformation Capital Initiative depends on sustained interest, legitimacy, and resourcing. In other words, the people it seeks to serve must pay attention to the investment logic, believe in its usefulness, and provide the initiative with the intellectual and financial capital to sustain momentum. While there are many factors enabling a Prototype to serve a catalytic function, storytelling, field building, and fundraising are critical. 
There is thus a need to define proof points-specific pieces of evidence produced or emerging from prototyping work. Not all such proof points will be equally important. Some are critical, whilst others are peripheral. There is thus value in sequencing proof points, starting with the most relevant first. In that sense, the Transformation Capital Initiative can be viewed as an entrepreneurial endeavour that comes into existence through a minimum viable product (MVP) approach.

\section{THE IDEAL PROTOTYPE}

The normative views described above inform the specifications of an ideal Prototype. This is a learning environment that (i) exhibits a high degree of congruency between the nature of Transformation Capital as a systemic investment logic and the intent declared for the system we seek to change, (ii) has practical aspects that allow learning to happen, and (iii) comes with tactical benefits for giving "runway" to the Transformation Capital Initiative. Specifically, the ideal Prototype has the following characteristics:

People: A Prototype will flourish if the space it creates is populated with people who share the same intent (with respect to systemic outcomes) and engage with a similar mindset (with respect to ways of working). Personal chemistry amongst the individuals engaged on behalf of the system-or of organizations seeking to induce change in that system-will act as a catalyst for collaboration.

Nature of Challenge: A Prototype will produce important learning if it is set in a context of interesting complexity. Such complexity is often found in systems characterized by a plurality of actors, relationships, and feedback loops and by a lack of obvious solutions to the systemic problems that need to be addressed. Cities, transportation systems, landscapes, agricultural value chains, national and regional economies, corporations, and industrial value chains are examples of such systems.

There are a number of other qualitative aspects to be considered. First, it must be possible to draw the system's boundaries in a way that allows the Prototype to retain a degree of manageability. Second, a Prototype should address an issue of high importance, ideally one that carries emotional value. This will make it easier to attract attention (incl. from the media and important stakeholders) and unlock funding. Finally, an ideal Prototype is set in a cultural context in which there is strong community orientation and in which positive social outcomes are part of society's utility function. This will facilitate stakeholder engagement, as the societal intent of Transformation Capital will be more readily understood.

Additionality: A Prototype will create additionality if it takes place in an environment that lacks investment capital of the type and/or quantity required for a systemic transformation, or where key actors lack the skills, tools, or mandate required for systemic investing.

Degree of Transactability: A Prototype will attract investors' attention and gain legitimacy if it offers a pathway to real-world investments. It will therefore be helpful if the Prototype operates in a system with a mature financial ecosystem, strong institutions (incl. rule of law), acceptable perceived risks, enabling policy environments, and strong human capacity.

Institutional Connectivity: A Prototype connected into an institutional structure-e.g. a multilateral mechanism, an important industry, an anchor corporation, etc-will find it easier to see its impact scaled further down the line. To that end, it can be fruitful to establish such connectivity from the outset, perhaps even designing the Prototype in collaboration with the representatives of such institutional structures. 
Operational Setting: A Prototype supported by an existing operational platform will find it easier to make steady progress, accomplishing the quick wins necessary to sustain momentum over time and building on the stories that keep stakeholders and the broader public engaged.

The above points apply to each Prototype in isolation. Yet each Prototype will be unique and offer a limited set of learning opportunities. Obviously, deploying capital in Switzerland and Sweden is very different from doing so in Cambodia and Cameroon. Likewise, different system types-landscapes, cities, corporations, transportation systems, etc-have very different characteristics, and deploying capital in these contexts will require tailored configurations of approaches, actors, and instruments. So it is important to build a cohort of Prototypes that fosters diversity and creates the potential to generate combinatorial learning effects.

\section{PROTOTYPING: A MEANS TO AN END}

While Prototypes are expected to produce impact in the systems in which they take place, they are ultimately a means to mainstreaming a system-transformative investment logic within a wider actor group. Proximally, such actors include anybody with a transformative agenda and a resource commitment. Ultimately, systemtransformative intent, mindsets, and capabilities should diffuse throughout the financial industry at large. How such bottom-up innovation can effectively scale is subject to further research and discovery. 


\section{REFERENCES}

- Buckley, W. (1968): Society as a Complex Adaptive System. In: Modern Systems Research for the Behavioral Scientist. Aldine.

- cf. Axilo: Optimal Capital Allocation to Strategic Innovation Options (OCASIO). Private Communications, May 2019.

- Farmer, J.D., et al. (2019): Sensitive intervention points in the post-carbon transition. Science, 12 Apr 2019: Vol. 364, Issue 6436, pp. 132-134.

- Fetherston, J., (2018). How to Close the \$2.5 Trillion SDG Investment Gap. BCG Cent. Public Impact. URL https://www.centreforpublicimpact.org/close-the-sdg-investment-gap-open-letter/.

- Hofstetter, D. (1 de July de 2019). Transformation Capital: A New Investment Logic for Catalyzing Systems Change. EITClimate-Kic, URL: https://www.climate-kic.org/insights/transformation-capital/

- IPCC (2018): Summary for Policymakers. In: Global Warming of $1.5^{\circ} \mathrm{C}$. An IPCC Special Report on the impacts of global warming of $1.5^{\circ} \mathrm{C}$ above pre-industrial levels and related global greenhouse gas emission pathways, in the context of strengthening the global response to the threat of climate change, sustainable development, and efforts to eradicate poverty [Masson-Delmotte, V., P. Zhai, H.-O. Pörtner, D. Roberts, J. Skea, P.R. Shukla, A. Pirani, W. Moufouma-Okia, C. Péan, R. Pidcock, S. Connors, J.B.R. Matthews, Y. Chen, X. Zhou, M.I. Gomis, E. Lonnoy, T. Maycock, M. Tignor, and T. Waterfield (eds.)]. World Meteorological Organization, Geneva, Switzerland.

- IPCC (2018): Annex I: Glossary - Special Report: Global Warming of $1.5^{\circ} \mathrm{C}$, https://www.ipcc.ch/sr15/ chapter/glossary/ (accessed July 24, 2019)

- Mazzucato, M. and Penna, C.C.R. (2015): Mission-Oriented Finance for Innovation: New Ideas for Investment-Led Growth. Policy Network. 1st edition.

- Paris Agreement, Paris, 12 December 2015, United Nations Treaty Series, Registration No. 54113.

- Schot, J. et al. (2019): Transforming Experimentation: Experimental Policy Engagements and Their Transformative Outcomes. Published by University of Sussex - Business School, Transformative Innovation Policy Consortium (TIPC), University of Utrecht - Centre for Global Challenges.

- UNCTAD (2014), World Investment Report 2014 -Investing in the SDGs: An Action Plan, United Nations, Switzerland.

- Whitley, S. et al. (2018): Making finance consistent with climate goals. Insights for operationalising Article 2.1c of the UNFCCC Paris Agreement. Published by ODI, WRI, RMI, and E3G.

- World Economic Forum (2019), The Global Risks Report 2019 - 14 $4^{\text {th }}$ Edition. 